\title{
Crystal and molecular structure of 4-amino-4-carboxyl thiapyran hydrobromide*
}

\author{
K. K. CHACKO AND S. K. BHATTACHARJEE \\ Centre of Advanced Study in Physics, \\ University of Madras, Madras-600025, India \\ and \\ R. ZAND \\ Biophysics Research Division, \\ University of Michigan, Ann Arbor, U.S.A.
}

(Received March 15, 1975)

\begin{abstract}
4-Amino-4-carboxylthiapyran hydrobromide crystallizes in the monoclinic space group $P 2_{1} / m$, with $a=9.72 \AA, b=6.60 \AA$ and $c=7.10 \AA, \beta=94.8^{\circ}$ and $Z=2$. The structure was solved by the heavy atom method with 786 observed reflections and refined to an $R$ of 0.076 . There is an interesting weak interaction which the hetero sulfur atom of the thiapyran ring makes with a symmetry related amino nitrogen $(\mathrm{N} \ldots \mathrm{S}$ distance $3.34 \AA$ ) which significantly affects the "puckered-chair" conformation of the thiapyran ring.
\end{abstract}

\section{Introduction}

Structural determinations of a series of compounds of 1-aminocycloalkane carboxylic acids have already been reported with a view to understanding the packing and conformational features of these systems (Chacko et al., 1971a,

* Contribution No. 405 from the Centre of Advanced Study in Physics, University of Madras, Madras-600025, India.

1976 Plenum Publishing Corporation, 227 West 17th Street, New York, N.Y. 10011. No part of this publication may be reproduced, stored in a retrieval system, or transmitted, in any form or by any means, electronic, mechanical, photocopying, microfilming, recording, or otherwise, without written permission of the publisher. 
1971b; Srikrishnan et al., 1971; Mallikarjunan et al., 1972). X-ray investigation of the hydrobromide derivative of 4-amino-4-carboxylthiapyran (hereinafter called 4-THIA HBR) was carried out to understand the conformational and packing changes that are introduced into the cyclohexane system when a hetero atom like sulfur replaces a methylene group in the ring. One such study has already been reported, the five-membered thiazolidine ring system, thioproline, where it has been observed that thioproline (Chacko, 1974) and proline (Kayushina and Vainshtein, 1965) have marked differences in their packing features.

\section{Experimental}

Rotation, Weissenberg and precession photographs were taken with $\mathrm{Cu} K \alpha$ radiation $(\lambda=1.5418 \AA)$. The crystal data are given below:

$\begin{array}{ll}\text { Crystal system } & \text { Monoclinic } \\ \text { Unit-cell dimensions } & a=9.72(1) \AA \\ & b=6.60(1) \AA \\ & c=7.10(1) \AA \\ & \beta=94.8(5)^{\circ} \\ \text { Space group } & P 2_{1} / m \\ \text { Molecular formula } & \mathrm{C}_{6} \mathrm{H}_{12} \mathrm{BrNO}_{2} \mathrm{~S} \\ Z & 2 \\ D_{m} & 1.77 \mathrm{gcm}^{-3} \\ D_{c} & 1.77 \\ \mu(\mathrm{Cu} K \alpha) & 84 \mathrm{~cm}^{-1} \\ F(000) & 244\end{array}$

The intensities were collected about $b$ for $h K l(K, 0$ through 5$)$ and about $a$ for $H k l(H, 0$ and 1$)$ by the multiple-film equi-inclination method. The crystal used for the $b$-axis data had a cross section of nearly $0.2 \times 0.2 \mathrm{~mm}$ and for the $c$-axis $0.25 \times 0.2 \mathrm{~mm}$. The intensities were measured visually and corrected for Lorentz and polarization factors and for spot shape. The common reflections were used to put the data on to a single scale (Rollett and Sparks, 1960) and there was a total of 786 reflections.

\section{Structure determination and refinement}

The cell dimensions of 4-THIA HBR are nearly the same as those of 1-aminocyclohexane-1-carboxylic acid hydrochloride (hereinafter called 1-HEX HCL) reported by Chacko et al. (1971b), and the space group was initially assumed to be $P 2_{1}$ as in 1 -HEX $\mathrm{HCl}$. [ It was later found necessary to reinvestigate 1-HEX HCL in the space group $P 2_{1} / m$ (Chacko et al., 1975).] The three-dimensional intensity data were used to compute a Patterson 


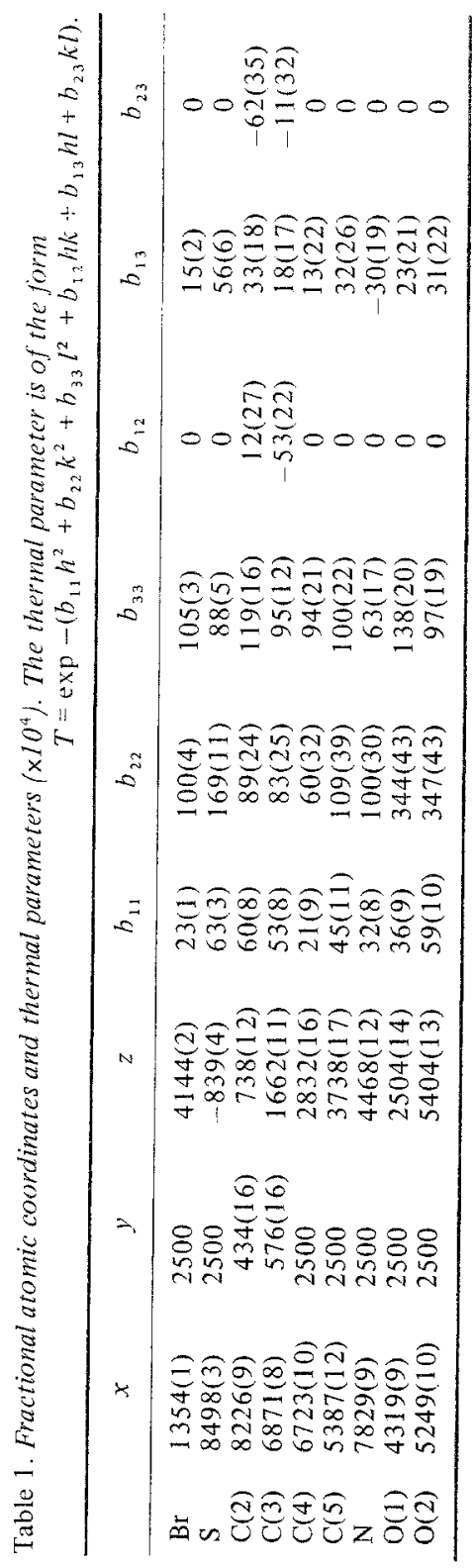


Table 2. Coordinates of the hydrogen atoms

\begin{tabular}{rrrrcc}
\hline & $x$ & $y$ & $z$ & $B\left(\AA^{2}\right)$ & Bonded to \\
\hline $\mathrm{H}(1)$ & 0.876 & 0.250 & 0.398 & 1.36 & $\mathrm{~N}$ \\
$\mathrm{H}(2)$ & 0.772 & 0.374 & 0.526 & 1.36 & $\mathrm{~N}$ \\
$\mathrm{H}(3)$ & 0.335 & 0.250 & 0.296 & 2.85 & $\mathrm{O}(1)$ \\
$\mathrm{H}(4)$ & 0.823 & -0.099 & -0.005 & 2.03 & $\mathrm{C}(2)$ \\
$\mathrm{H}(5)$ & 0.907 & 0.040 & 0.185 & 2.03 & $\mathrm{C}(2)$ \\
$\mathrm{H}(6)$ & 0.603 & 0.052 & 0.056 & 1.80 & $\mathrm{C}(3)$ \\
$\mathrm{H}(7)$ & 0.679 & -0.073 & 0.258 & 1.80 & $\mathrm{C}(3)$ \\
\hline
\end{tabular}

map to locate the heavy atoms bromine and sulfur. The bromine coordinates were close to the chlorine coordinates of 1-HEX HCL (Chacko et al. 1971b). The Patterson analysis* also indicated that the sulfur was on the same plane as bromine $(y=1 / 4)$ from the bromine-sulfur interactions. A heavy atom-phased Fourier analysis revealed the rest of the atoms in the structure, which gave an initial $R$-value of 0.35 for all the nonhydrogen atoms in the structure.

Full-matrix least-squares refinement (Gantzel et al., 1961) with isotropic temperature factors for all atoms in the noncentric space group $P 2_{1}$ gave highly unreasonable bond lengths and angles for the structure. Further refinement was therefore carried out in the centric space group $P 2_{1} / m$ (the molecules could have a mirror plane passing through the carboxyl group, nitrogen and sulfur atoms which fall on the space group mirror at $y=1 / 4$ ) to an $R$-value of 0.11 . The hydrogens were located from a difference Fourier synthesis computed at this stage. The structure was further refined with anisotropic temperature factors for all the nonhydrogen atoms and inclusion of hydrogen atom parameters, which were not refined. The weighting scheme employed was that of Cruickshank et al. (1961), given by $w=1 /\left(A+\left|F_{o}\right|+\right.$ $\left.C\left|F_{o}\right|^{2}\right)$ where the constants $A$ and $C$ were set values equal to 30.0 and 0.02 respectively. After three cycles of refinement $R$ dropped to a final value of 0.076 .

Scattering factors were taken from the International Tables for X-ray Crystallography (1962). Anomalous dispersion correction factors applied to $\mathrm{Br}^{-}$and $\mathrm{S}$ are those given by Cromer and Liberman (1970). The final positional and thermal parameters are given in Table 1 and Table 2 lists the hydrogen atom coordinates. The $b_{22}$ components of the anisotropic parameters of oxygen atoms correspond to rms displacements of about twice that of $C(5)(0.25 \AA$ vs $0.15 \AA)$. A difference Fourier synthesis was computed

* The Patterson sections close to $V=0$ were used for locating peaks corresponding to the bromine-light atom vector interactions for those atoms that are expected to fall on the mirror for the space group $P 2_{1} / \mathrm{m}$. The Patterson clearly indicated the peaks on the $V=0$ section itself. This proved conclusively that the correct space group is $P 2_{1} / \mathrm{m}$ rather than $P 2_{1}$ 
(excluding the oxygen atoms from the structure factor); it did not show disorder and hence the large displacements are merely thermal effects on these atoms.

\section{Discussion of the structure}

Intramolecular features. Bond lengths and angles listed in Table 3 agree fairly well with the standard values found in the literature. The average $\mathrm{C}-\mathrm{C}$ bond length of the thiapyran ring of $1.527 \AA$ is close to the value of $1.533 \AA$, which is the average $\mathrm{C}-\mathrm{C}$ bond length observed in $n$-alkanes (Bartell and Kohl, 1963). The C(2)-S distances of $1.798 \AA$ agree closely to the value of $1.81 \AA$ (sum of the covalent radii of carbon and sulfur as given by Pauling, 1960). The C-S-C angle of $98.7^{\circ}$ agrees well with the corresponding angle of $99.0^{\circ}$ in the structure of 1,4-dithiane (Marsh, 1955) and $97.5^{\circ}$ in the structure of 4-amino-4-carboxylthiapyran (hereinafter called 4-THIA) of Bhattacharjee et al., 1975. The average $\mathrm{C}-\mathrm{C}-\mathrm{C}$ bond angle of $113.1^{\circ}$ of the thiapyran ring shows that it is larger than the value of $111.5^{\circ}$ for cyclohexane chair conformation (Bixon and Lifson, 1967). The slight increase in the mean value of the $\mathrm{C}-\mathrm{C}-\mathrm{C}$ bond angle seems to be a compensating feature for the small value of the $\mathrm{C}-\mathrm{S}-\mathrm{C}$ valency angle. A similar feature is observed in the structure of 4-THIA (Bhattacharjee et al., 1975).

The carboxyl group exists in this structure in the unionized form with the amino nitrogen in the $\mathrm{NH}_{3}^{+}$state; the amino nitrogen is in the plane of the carboxyl group and the $\mathrm{C}(4)$ atoms (space-group symmetry demands that it be so). The $\mathrm{C}(4)-\mathrm{N}$ distance of $1.515 \AA$ is within the $2 \sigma$ level of significance from the value of $1.487 \AA$ for the $C^{\alpha}-\mathrm{N}$ distance observed in amino acids (Marsh and Donohue, 1967). The $\mathrm{C}(5)-\mathrm{C}(4)-\mathrm{N}$ angle of $104.8^{\circ}$ is significantly smaller than the expected tetrahedral angle.

The thiapyran ring in this structure exists in a "puckered-chair" conformation as indicated by the torsion angles about bonds given in Table 4 . It is expected that substitution of a hetero atom like sulfur would enhance

Table 3. Bond lengths $(\AA)$ and bond angles (deg)

\begin{tabular}{lllr}
\hline $\mathrm{S}-\mathrm{C}(2)$ & $1.798(10)$ & $\mathrm{C}(2)-\mathrm{S}-\mathrm{C}\left(2^{\prime}\right)$ & $98.7(6)$ \\
$\mathrm{C}(2)-\mathrm{C}(3)$ & $1.523(13)$ & $\mathrm{S}-\mathrm{C}(2)-\mathrm{C}(3)$ & $113.5(7)$ \\
$\mathrm{C}(3)-\mathrm{C}(4)$ & $1.531(11)$ & $\mathrm{C}(2)-\mathrm{C}(3)-\mathrm{C}(4)$ & $114.1(7)$ \\
$\mathrm{C}(4)-\mathrm{C}(5)$ & $1.497(17)$ & $\mathrm{C}(3)-\mathrm{C}(4)-\mathrm{C}\left(3^{\prime}\right)$ & $112.1(7)$ \\
$\mathrm{C}(4)-\mathrm{N}$ & $1.515(15)$ & $\mathrm{C}(3)-\mathrm{C}(4)-\mathrm{C}(5)$ & $110.0(7)$ \\
$\mathrm{C}(5)-\mathrm{O}(1)$ & $1.301(16)$ & $\mathrm{C}(3)-\mathrm{C}(4)-\mathrm{N}$ & $108.9(7)$ \\
$\mathrm{C}(5)-\mathrm{O}(2)$ & $1.202(15)$ & $\mathrm{C}(5)-\mathrm{C}(4)-\mathrm{N}$ & $104.8(7)$ \\
& & $\mathrm{C}(4)-\mathrm{C}(5)-\mathrm{O}(1)$ & $112.5(7)$ \\
& & $\mathrm{C}(4)-\mathrm{C}(5)-\mathrm{O}(2)$ & $126.5(8)$ \\
& & $\mathrm{O}(1)-\mathrm{C}(5)-\mathrm{O}(2)$ & $121.0(7)$ \\
\hline
\end{tabular}




\begin{tabular}{lc}
$\begin{array}{c}\text { Table 4. Torsion angles } \\
\text { thiapyran ring }\end{array}$ & (deg) of the \\
\hline $\mathrm{C}\left(3^{\prime}\right)-\mathrm{C}(4)-\mathrm{C}(3)-\mathrm{C}(2)$ & $57.0(9)$ \\
$\mathrm{C}(4)-\mathrm{C}(3)-\mathrm{C}(2)-\mathrm{S}$ & $-59.2(9)$ \\
$\mathrm{C}(3)-\mathrm{C}(2)-\mathrm{S}-\mathrm{C}\left(2^{\prime}\right)$ & $52.4(7)$ \\
Mean torsion angle $\left(\phi_{\mathrm{av}}\right)$ & 56.2
\end{tabular}

the puckering of the ring which is a consequence of the well-known small value of the $\mathrm{C}-\mathrm{S}-\mathrm{C}$ valency angle (Romers, et al., 1969). The mean torsion angle $\left(\phi_{a v}\right)$ of $56.2^{\circ}$ indicates enhancement in puckering as it is larger than the value of $54.7^{\circ}$ expected for the chair form of cyclohexane (Bixon and Lifson, 1967). However, the puckering is expected to be larger than that observed in this structure, with a value of about $59^{\circ}$. In the structure of 4-THIA (Bhattacharjee et al., 1975) the value of $\phi_{a v}$ for the thiapyran ring is $58.9^{\circ}$. The $\mathrm{C}(2), \mathrm{C}(3), \mathrm{C}\left(2^{\prime}\right)$, and $\mathrm{C}\left(3^{\prime}\right)$ atoms of the thiapyran ring in this structure form a plane with the $\mathrm{C}(4)$ and $\mathrm{S}$ atoms displaced on opposite sides of the plane by 0.66 and $0.85 \AA$ respectively. The corresponding deviations in the structure of 4-THIA are 0.66 and $0.92 \AA$ respectively, which also indicate

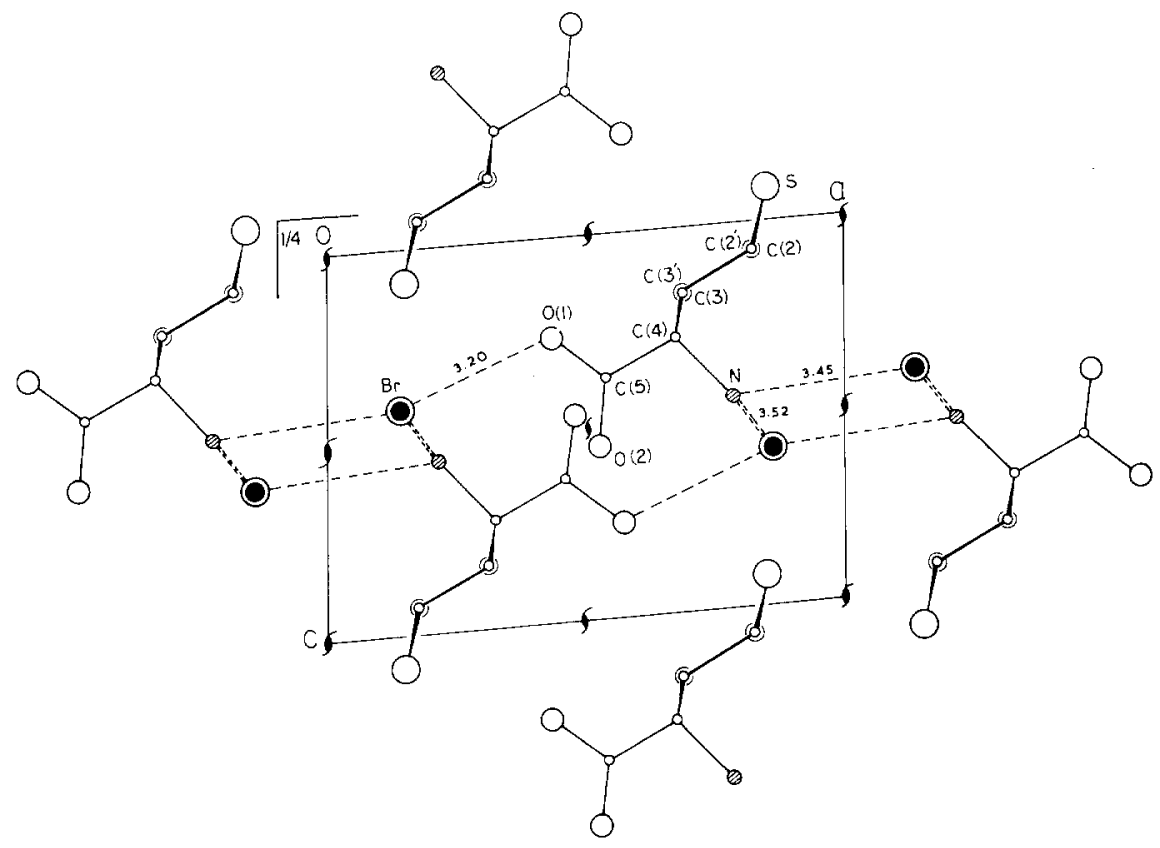

Fig. 1. Projection of structure down $b$ axis. 
that the puckering in the present structure is significantly less than the expected amount. The reason for this is probably because of a weak $\mathrm{N}-\mathrm{H} \ldots \mathrm{S}$ interaction of $3.34 \AA$ which the hetero sulfur makes with a symmetry-related amino nitrogen, as discussed in the following section.

Intermolecular features. The structure projected down $b$ is given in Fig. 1 . The protonated amino group $\left(\mathrm{NH}_{3}^{+}\right)$takes part in three hydrogen bonds with symmetry-related bromine ions $(\mathrm{Br}(\mathrm{ii}), \mathrm{Br}(\mathrm{iii})$ and $\mathrm{Br}(\mathrm{iv})$ at distances of $3.45 \AA, 3.52 \AA$ and $3.52 \AA$ respectively, two of which are mirror symmetry related hydrogen bonds. The hydrogen bond distances and angles are given in Table 5. Figure 2 gives the projection down the $\mathrm{C}(4)-\mathrm{N}$ bond showing the hydrogen bond directions. A possibility of bifurcated hydrogen bonds is considered which the amino hydrogen $\mathrm{H}(2)$ makes with $\mathrm{Br}(\mathrm{iii})$ and sulfur $\mathrm{S}(\mathrm{v})$, the corresponding $\mathrm{H}(2) \ldots \mathrm{Br}$ and $\mathrm{H}(2) \ldots \mathrm{S}(\mathrm{v})$ distances being 2.67 and $2.93 \AA$ respectively. Because of mirror symmetry at $y=1 / 4$, hydrogen $\mathrm{H}\left(2^{\prime}\right)$ also has identical contacts with $\mathrm{Br}(\mathrm{iv})$ and $\mathrm{S}(\mathrm{v})$. However, the hydrogen to sulfur distance of $2.93 \AA$ shows that it may not be strictly called a hydrogen bond as it is only $0.02 \AA$ less than the sum of the van der Waals radii of sulfur and hydrogen, which are assumed to be 1.75 and $1.2 \AA$ respectively [Pauling's (1960) value of sulfur of $1.85 \AA$ is considered to be an overestimated value (see Srinivasan and Chacko, 1967)]. However, since sulfur has contacts with two protons which are mirror related, the possibility of a weak interaction between N...S cannot be ruled out. It is also worthwhile to point out that the N...S distance of $3.34 \AA$ is less than the average value of $3.4 \AA$ for $\mathrm{N}-\mathrm{H} \ldots \mathrm{S}$ type of hydrogen bonds reported by Srinivasan and Chacko (1967). Figure 2 shows that nitrogen has, interestingly, a highly symmetric environment. The hydroxyl oxygen atom

Table 5. Hydrogen bond lengths $(\AA)$ and angles (deg)

\begin{tabular}{|c|c|c|c|c|c|c|c|}
\hline$D-\mathrm{H} \ldots A$ & \multicolumn{2}{|c|}{$D \ldots A$} & $\mathrm{H} \ldots A$ & \multicolumn{2}{|c|}{$C-D \ldots A$} & $D-\mathrm{H} \ldots A$ & $\mathrm{H}-D \ldots A$ \\
\hline $\mathrm{O}(1)-\mathrm{H}(3) \ldots \mathrm{Br}(\mathrm{i})$ & & 3.20 & 2.18 & \multicolumn{2}{|c|}{116.6} & 176 & 3 \\
\hline $\mathrm{N}-\mathrm{H}(1) \ldots \mathrm{Br}(\mathrm{ii})$ & & 3.45 & 2.51 & \multicolumn{2}{|c|}{126.4} & 157 & 16 \\
\hline $\mathrm{N}-\mathrm{H}(2) \ldots \mathrm{Br}(\mathrm{iii})$ & & 3.52 & 2.67 & \multicolumn{2}{|c|}{110.1} & 143 & 27 \\
\hline $\mathrm{N}-\mathrm{H}\left(2^{\prime}\right) \ldots \mathrm{Br}(\mathrm{iv})$ & & 3.52 & 2.67 & \multicolumn{2}{|c|}{110.1} & 143 & 27 \\
\hline $\mathrm{N}-\mathrm{H}(2) \ldots \mathrm{S}(\mathrm{v})$ & & 3.34 & 2.93 & \multicolumn{2}{|c|}{146.2} & 106 & 57 \\
\hline $\mathrm{N}-\mathrm{H}\left(2^{\prime}\right) \ldots \mathrm{S}(\mathrm{v})$ & & 3.34 & 2.93 & \multicolumn{2}{|c|}{146.2} & 106 & 57 \\
\hline \multicolumn{8}{|c|}{ Symmetry code } \\
\hline & (i) & $x$ & $y$ & & $z$ & & \\
\hline & (ii) & $1+x$ & $y$ & & $z$ & & \\
\hline & (iii) & $1-x$ & $1 / 2+$ & & $1-z$ & & \\
\hline & (iv) & $1-x$ & $y-$ & $-1 / 2$ & $1-z$ & & \\
\hline & (v) & $x$ & $y$ & & $1+z$ & & \\
\hline
\end{tabular}




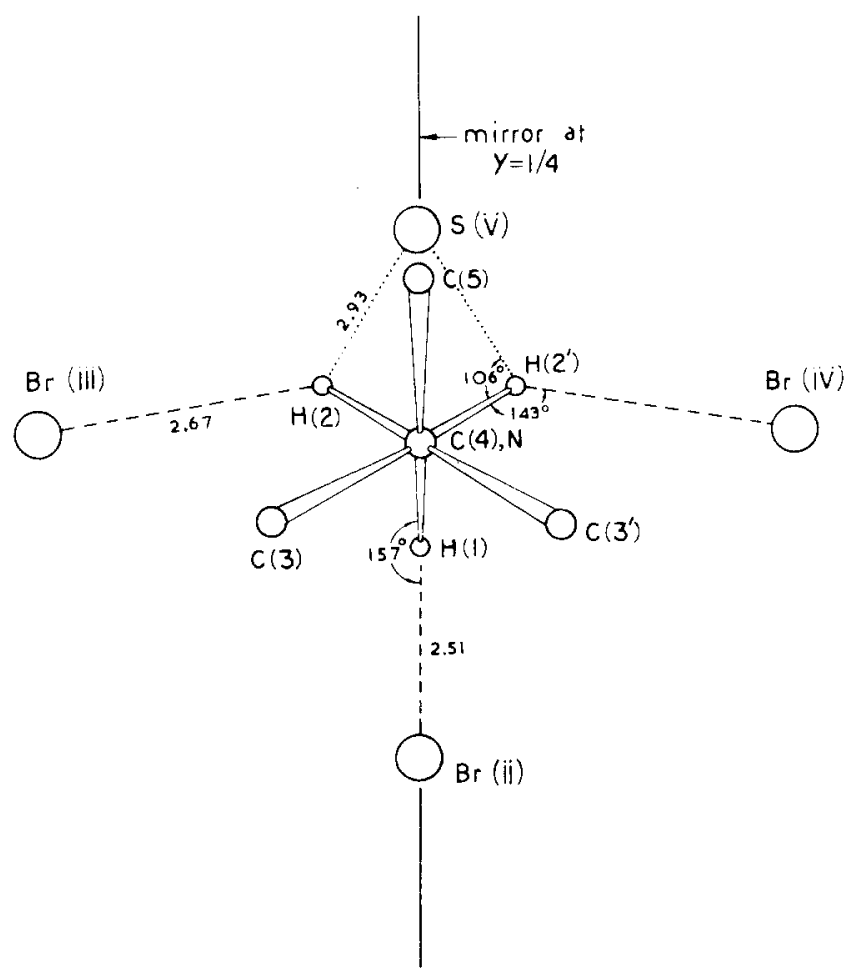

Fig. 2. Projection down $\mathrm{C}(4)-\mathrm{N}$ bond.

$O(1)$ forms a hydrogen bond of $3.20 \AA$ with $\operatorname{Br}(i)$. From the nature of the hydrogen-bonding scheme, one also comes to the conclusion that the packing of the structure favours a centric space-group symmetry rather than a noncentric one. The packing of 4-THIA HBR is very similar to that in 1-HEX HCL (Chacko et al., 1975) and, as expected, the maximum deviation in packing between these structures is for atoms $\mathrm{C}(4)$ of 1-HEX HCL and sulfur of the thiapyran ring and also for the immediate neighbor atoms of $\mathrm{S}$. The $\mathrm{N}$ and $\mathrm{O}(2)$ also show significant positional displacements in both these structures.

\section{Acknowledgments}

One of us (S.K.B.) would like to thank the University Grants Commission, New Delhi, India, for financial assistance. This work was supported in part by N.S.F. Grant CB21435 to R. Zand. 


\section{References}

Bartell, L. S. and Kohl, D. A. (1963) J. Chem. Phys. 39, 3097.

Bhattacharjee, S. K., Chacko, K. K. and Zand, R. (1975) in press.

Bixon, M. and Lifson, S. (1967) Tetrahedron 23, 769.

Chacko, K. K. (1974) Cryst. Struct. Comm. 3, 561.

Chacko, K. K., Srinivasan, R. and Zand, R. (1971a) J. Cryst. Mol. Struct. 1, 213.

Chacko, K. K., Stinivasan, R. and Zand, R. (1971b) J. Cryst. Mol. Struct. 1, 261.

Chacko, K. K., Srinivasan, R. and Zand, R. (1975). J. Cryst. Mol. Struct. 5, 353.

Cromer, D. T. and Liberman, D. (1970) J. Chem. Phys. 53, 1891.

Cruickshank, D. W. J., Pilling, D. E., Bujosa, A., Lovell, F. M. and Truter, M. R. in Computing Methods and the Phase Problems (Pergamon Press, Oxford, 1961, p. 32).

Gantzel, P. K., Sparks, R. A. and Trueblood, K. N. (1961) Program UCLALS-1, University of California.

International Tables for X-ray Crystallography, Vol. III (Birmingham, Kynoch Press, 1962).

Kayushina, R. L. and Vainshtein, B. K. (1965) Kristallografiya, 10, 833.

Mallikarjunan, M., Chacko, K. K. and Zand, R. (1972) J. Cryst. Mol. Struct. 2, 53.

Marsh, R. E. (1955) Acta Cryst. 8, 91.

Marsh, R. E. and Donohue, J. (1967) Advanc. Protein Chem. 22, 235.

Pauling, L. The Nature of the Chemical Bond. 3rd ed. (Cornell University Press, Ithaca, $1960)$.

Rollett, J. S. and Sparks, R. A. (1960) Acta Cryst. 13, 273.

Romers, C., Altona, C., Buys, H. R. and Havinga, E. in E. L. Eliel and N. L. Allinger, eds., Topics in Stereochemistry, Vol. IV, (Wiley-Interscience, New York, 1969, p. 39).

Srikrishnan, T., Srinivasan, R. and Zand, R. (1971) J. Cryst. Mol. Struct. 1. 199.

Srinivasan, R. and Chacko, K. K. in G. N. Ramachandran, ed., Conformation of Biopolymers, (Academic Press, New York, 1967, p. 607).

British Library Lending Division Supplementary Publication No. 600157 contains 6 pages of structure factor tables on 1 microfiche 